\title{
SPACE, TIME, AND OIL
}

\section{The Global Petroleumscape}

\section{Carola Hein}

Industrially drilled petroleum and its refined products have transformed life and landscapes around the world in ways that are often not visible or recognized. It is difficult to see petroleum's shaping force when it forms part of so many of the objects and materials that surround us: the fabric of our clothes, the toys of our children, the asphalt on which we drive, even the food we eat. Petroleum's influence on daily life is often indirect, such as when its availability influences choices about where one should live or how one should spend one's leisure time. We take its presence and what it makes possible for granted and have only recently started to track its impact through $\mathrm{CO}_{2}$ emissions, plastic waste, and petrochemical fertilizers. Yet, petroleum and its derivatives have been at work for a century and a half, powering factories, building cities, shaping landscapes, and sustaining nation-states. The diverse spaces of petroleum-oil fields, refineries, company headquarters, gas stations, housing, heritage sites, and even philanthropic structures - are dispersed around the world in uneven ways, facilitating everyday life for some and placing burdens on others. The spatial realities of petroleum and its representation have been game changers in the history of humans. Space is particularly important in the permeation of petroleum use; once established, physical infrastructures and spaces can shape future developments. Analyzing the oil revolution and the way it shaped and used buildings, cities, and landscapes, from underground to atmosphere, is important as we face the need to transition to a new energy landscape and imagine the possibilities and challenges of a post-oil future.

The investigations in this volume are based on the concept of a global palimpsestic petroleumscape $^{1}$ : a layered physical and social landscape that reinforces itself over time through human action and connects urban and rural spaces, culture and nature, materials and intangible practices. An interest in space and spatial practices in the built environment has been a constant in my research in architectural and urban history. Early in my career, as I explored topics as diverse as the construction of business districts in the 1950s and 1960s, the question of a capital for Europe, and the works of the French planner Maurice Rotival, petroleum continually emerged as an agent of change. Researching port cities and the impact of commodity flows on the built environment, I started to address the question of petroleum more 
directly. With a Guggenheim fellowship in 2007-2008, I began to theorize the concept of the petroleumscape. With this concept in mind, I conducted research on the spaces of petroleum in various cities, including Rotterdam, Dunkirk, and Philadelphia; I collaborated with colleagues and PhD students; I organized conference sessions and workshops. The contributors to this volume, many of whom attended the conference on the Global Petroleumscape in Delft in 2017, engage with the petroleumscape concept by revealing through case studies petroleum's role in organizing and imagining spaces globally.

Following a brief discussion of the materiality and agency of petroleum, this chapter introduces the concept of the petroleumscape as an attempt to theorize the role of petroleum in the built environment through the lenses of the spatial and the representational petroleumscape. It concludes by briefly introducing the chapters that form the three parts of the book.

\section{Petroleum as Material and Agent over Five Generations of the Petroleumscape}

The concept of the petroleumscape starts from the understanding that petroleum is a physical material with a pervasive impact on physical space in terms of architecture, cities, and landscapes, and is not a magic fluid that fuels economies without a spatial imprint. Petroleum, or "rock oil," is a natural product that bubbles up from the ground, and humans have long used it for specialized purposes in ways that foreshadow our uses today. Incendiary weapons such as "Greek fire" anticipated our current use of oil for warfare, lighting, and warming. Bitumen, once used to make pools and basins watertight in Mesopotamia and to mummify bodies in Egypt, today appears in asphalt street cover, roofing materials, and waterproofing. And the historic use of petroleum as a medicine precedes more recent pharmaceutical and cosmetic uses; for some 150 years, people have been applying Vaseline petroleum jelly to dry skin and minor wounds. This materiality of petroleum has shaped physical space and people's lifestyles around the world.

Oil extraction, production, and resale are all spatially anchored through extraction, transformation, transportation, storage, and consumption. Petroleum interests have created and promoted geopolitical conflict. The drive to access petroleum sources has led to numerous wars and reshaped the boundaries and structure of nations. Transnational companies have pursued their interests, often forcing the hands of nation-states, influencing internal politics and policies. Conflicting interests within nations have spurred internal conflicts, visible in ongoing discussions around the future energyscape. Although petroleum has been at the origin of numerous conflicts and although its actors are multiple and have competing interests, the history of petroleum as an agent of spatial transformation has been one of seemingly unhindered and continual growth and expansion.

With industrial petroleum's end in sight, its past merits scrutiny. The petroleumscape did not emerge as if squeezed from a tube; rather, it was built incrementally, with one generation supporting the next. Industrial drilling provided the initial foundation for the development of the modern petroleumscape. In 1859, on Oil Creek in Pennsylvania (later known as Titusville), Edwin Laurentine Drake developed the technology of drilling wells, providing access to deeper oil fields and giving rise to the first generation of the petroleumscape (1859-1910). The industry at this point revolved mostly around kerosene, a petroleum distillate, which eventually replaced whale oil for lighting, and provided select countries 
with a head start for building new infrastructures and developing petroleum-related knowledge. Industrialized drilling made petroleum available around the world for a huge number of purposes, but there was no large demand for oil before the arrival of advanced refining techniques and other technological inventions. In particular, gasoline-powered automobiles and their later mass production along assembly lines led to a new demand for petroleum as an engine lubricant, and consumers and companies alike pushed for further oil drilling.

The second generation (1910-1940) saw the expansion of existing installations to other parts of the world, notably the Middle East, often through colonial networks. Access to petroleum sources, knowledge of its physical qualities, creativity, and innovation in developing new products and increased capacity of distribution have led to the growth of huge corporations and have shaped the form and function of entire nation-states. The need to find new applications and consumers led to the third generation (1940-1970), which included the extensive introduction of plastics into architecture and everyday life. Petroleum became the most important fossil fuel of the twentieth century. The emergence of critical voices brought about the fourth generation (1970-2000), at a time when spaces on sea and land had become saturated with petroleum-related structures. The fifth generation (2000-) has seen multiple attempts to overcome the petroleumscape, yet with only partial success as the increased demand for a growing number of petroleum products spurred the development of new technologies for finding oil and extracting it from more and more difficult sites on land and sea, in ice, rainforests, or from shale formations.

The oil industry has produced numerous powerful global players, who control interconnected oil spaces around the world. Well-capitalized operators and politically powerful nations have managed the consolidation of the sector. They have been capable of investing in technical innovation and professional knowledge and able to endure failures, disasters, wars, and price busts, and able to balance income and investment across their global supply chains. The petroleum industry spans multiple areas of intervention, the so-called upstream, midstream, and downstream activities. The upstream sector includes oil prospecting and extraction. Its sites are often in rural areas or places that are difficult to access. The midstream sector includes road, rail, and pipeline infrastructures that transport petroleum and its products to and from refineries, often on a global scale. The downstream sector includes oil refining and processing as well as marketing and some midstream activities, all of which are important in distributing oil products to consumers. Each of these sectors has similar functions and typologies around the world, with its own location, typology, built form, and function. They interconnect to form a single landscape while engaging in unique ways with local needs and practices.

Among the best-known and largest contemporary oil companies is Exxon Mobil. Its roots go back to 1863, when John D. Rockefeller joined a Cleveland-based oil-refining business that in 1870 became the Standard Oil Company. By 1880, it controlled the refining of 90-95 percent of all oil in the US. Nine trustees, including Rockefeller, created the Standard Oil Trust in 1882 from various companies engaged in producing, refining, and marketing oil. The company became the image of economic concentration and control and successfully expanded beyond national borders, making petroleum the primary source of energy around the world. In 1911, enforcement of federal anti-trust laws led to its dissolution. The pieces of the complex themselves became global giants, including Exxon, Mobil, Amoco, and others (some have reunited in subsequent years). The history of Exxon and other giant oil companies, including Shell, BP, and TOTAL, is the object of important 


\section{Carola Hein}

historical studies and corporate publications, but these studies do not engage in a close exploration of the role of space as a system. ${ }^{2}$

Petroleum practices depend on small and large businesses as well as national governments with differing degrees of control over land, funds, and laws. While oil companies are active on a global scale, they need governments to provide access to local spaces and they depend on national infrastructures, policies, and legal frameworks. Their diverse interests create multiple transnational linkages and friction points. Oil companies and governments have closely collaborated at home and in colonial settings, leading, for example, to British government support for the Anglo-Persian Oil Company shortly before World War I under the influence of Winston Churchill, and the Compagnie Française des Pétroles founded in 1924 and today known as TotalFinaElf. Oil companies and national governments have also come into conflict; numerous nationalization movements around the world have brought refineries and oil exploitation originally developed by private companies into the hands of new nations. The expropriations of petroleum reserves, oil facilities, and companies in Mexico, Suez, and Abadan are examples.

The discovery and ownership of petroleum, the specialized knowledge and equipment required, the enormous amounts of funding generated and consumed have brought about new nations and changed global power balances. The global leadership of oil business in Europe and the US peaked in the nineteenth and early twentieth centuries. Other countries, like China, discovered oil later, but have already largely depleted their national sources, making them important agents in global petroleum extraction. The discovery of large oil fields in the Middle East, Venezuela, Nigeria, and Russia created new global players with national economies largely dependent on petroleum income. In 1960, some of them, including Iran, Iraq, Kuwait, Saudi Arabia, and Venezuela, formed a cartel, the Organization of the Petroleum Exporting Countries (OPEC), to control oil prices and flow. The discovery of oil in the North Sea further changed the global spaces of oil, giving countries like Norway, the UK, and the Netherlands (through gas) new riches, and effectively leading to a redefinition of maritime territories and laws.

The exploitation, transformation, transportation, use, and even the cleanup of oil require collaboration among powerful actors. The oil business started out as a private business venture, but World War I was a turning point, as militaries depended on gasoline for their ships, tanks, trucks, and cars. The growing political importance of oil-and its geopolitical implications-made it a major factor in colonialism and wars-including the two world wars. Wartime creativity promoted the use of petroleum for a multitude of new products. Improvements in refining technology and chemistry provided the foundation for transforming petroleum into a rapidly increasing number of new petroleum-based products that did not involve burning it, including vinyl flooring, paint, and plastics; fibers such as nylon, acrylic, and polyester; and microplastics like microbeads used in body scrubs and toothpastes. This ability to create new products meant that oil companies could nimbly adapt to changing societal demands.

Petroleum and its multiple spaces influence global politics and economy, but also society and culture. Its impact on space and society depends on national and local efforts and perspectives. This is effectively illustrated through the use of terms such "oil crisis" or the "first oil shock" to describe events in 1973-1974. What was a crisis and a shock to the oil-consuming world, leading to the implementation of car-free Sundays in Germany and the Netherlands, had benefits for some of the producing countries, both within OPEC and 
beyond. The arrival of oil money in countries like Algeria led to the construction of new oil ports, such as Skikda, and the construction of new buildings and housing districts in capital cities, for example, in Tehran. New global players have also created new geographies of distribution. These shifts were often provoked by military campaigns or technological innovations - at times sponsored and brought about by the petroleum industry and its innovative research.

The presence of extremely powerful corporate and national actors has made the history of petroleum appear more coherent than it is. The petroleumscape's astounding longevity results from the feedback loop of overlaying functions in time. Wars and natural disasters have regularly destroyed or disconnected parts of the petroleumscape, yet industrial structures-refineries, oil tanks, oil ports—have been rapidly rebuilt, even under changing leadership, so that the old or new owners can continue to provide petroleum. Political shifts with territorial consequences, such as colonization, nationalization, or decolonization, have often involved profound disruptions. They have transformed global petroleum chains and flows, but they have not necessarily transformed the petroleumscape itself. Several major oil companies lost refineries and other installations to nationalization, but they rebuilt the missing structures rapidly in new locations to guarantee energy security. For a post-oil future, we need to generate new energy landscapes and new perspectives, yet even catastrophes like oil spills that demonstrate the dangers of the petroleumscape do not necessarily lead to changes: think of the Exxon Valdez catastrophe off Alaska in 1989 or the BP/Deepwater Horizon explosion in the Gulf of Mexico in 2010. At best, some of the petroleum-related disasters have led to localized changes, often increasing the pressure on other petroleum sites around the world.

Petroleum has come to facilitate movement and ease of life, but it has also jeopardized the future of human life on Earth and has advantaged some population groups over others. How we conceptualize petroleum spaces can help bridge the social science and humanities approaches to the study of petroleum's impact on society; it can also bridge the study of the past and the design of the future, given that space is a key agent in path dependence and feedback loops. The concept of the global petroleumscape, which I have introduced and refined in several articles and which will be further explored in a monograph, inspires reflections on the territorialities, spaces, and imaginaries of oil and on the spatial relevance of energy more generally.

\section{The Concept of the Petroleumscape}

The concept of the petroleumscape starts with the insight that the diverse spatial emanations of oil-including refineries, storage sites, office buildings, and gas stations-are connected through their relation to this single commodity and its group of industrial players. Connecting the actual places where oil is physically or financially present with the representation of these spaces and of the practices related to petroleum products, this concept aids understanding of the ways in which oil shapes behaviors and secures continuous production and expansion of its spaces. The physical structures and spaces of oil require extensive investment, and once funding has been sunk into the soil or the seafloor, economic and governance systems tend to reinforce earlier investments, reinforcing initial decisions. Oil imaginaries have served the promotion of lifestyles and everyday practices related to the consumption of petroleum products, creating a second feedback loop that reinforces the presence of the 


\section{Carola Hein}

petroleum industry through the participation of citizens for whom oil is a constant necessity. The benefits of cheap energy for travel and heating and of easy-to-use building materials have led citizens of different classes, races, cultures, genders, and ages around the world to embrace and develop the new urban and rural, natural and cultural, land- and sea-based petroleum spaces; they have encouraged the collaboration of groups whose goals are otherwise often conflicting. Careful promotion of the benefits and uses of petroleum products have helped reinforce widespread citizen buy-in, creating an energy culture that reinforces the spatial presence of the industry and leads to increased consumption in everyday life.

The concept of the petroleumscape brings architecture and the built environment into an already rich conversation. Conceptualizing the ways in which petroleum has shaped various architectural and urban spaces can be aided by the concept of planetary urbanization developed by the American urban theorist Neil Brenner and the Swiss sociologist Christian Schmid. ${ }^{3}$ Planetary urbanization includes the urbanization of the sea, a process that has been driven in part by petroleum interests. ${ }^{4}$ Arjun Appadurai suggested that the suffix "-scape" allows for an understanding of the "new global cultural economy as a complex, overlapping, disjunctive order that cannot any longer be understood in terms of existing centreperiphery models." 5 The excellent analysis of Michael Watts (referencing the work of Timothy Mitchell, Andrew Barry, and others) and his term oil assemblage connects oil with its territory, identifying a technological zone, while stopping short of discussing the designs and representations of actual buildings, cities, and landscapes. ${ }^{6}$ The use of the term "oil," however, is unfortunately imprecise. Research on the term will lead to sources and references that include many different types of oil. The concept of the petroleumscape is more precise as it addresses a specific commodity. The way it is used here encourages discussions of the role of space as an agent as well as consideration of how people have lived in the environments that petroleum has made possible. By studying the impact of oil on built form, we gain insight into the diverse spaces and temporalities of modernity in globally linked spaces.

This reading of the global petroleumscape is in line with Henri Lefebvre's understanding of space as socially produced and then appropriated by the powerful as a tool. ${ }^{7}$ In "The Production of Space," Lefebvre argues that space "in addition to being a means of production ... is also a means of control, and hence of domination, of power." ${ }^{8}$ In the case of petroleum, this dynamic is particularly evident. The spatial practices (the life of inhabitants in a space) and representations of space (the approaches of built environment professionals) intersect with the spaces of representation (the images and associations of the users) ${ }^{9}$; they are multiple (palimpsestic) layers of physical space and professional and public representation. While Lefebvre sets up a complex system, this book focuses on oil-related spatial practices of petroleum production, administration, retail, and consumption, and explores the representations of these petroleum spaces. A fuller analysis of the represented petroleumscape in our everyday culture, including everyday language, is still needed.

The petroleumscape has emerged through the collaboration of diverse actors as shown in the infographic (Figure 1.1) and it has become an actor itself. The presence of the petroleumscape often attracts additional functions - a secondary petroleumscape-which reinforces the presence of the oil infrastructures. Since first proposing the concept of the petroleumscape a decade ago, I have increasingly come to see the petroleumscape as singular (rather than plural), composed of multiple layers and aspects that combine into one overarching landscape. Each of these spatial layers has similar functions and typologies (style, location, or architectural form) interconnecting around the world. Together, these layers 


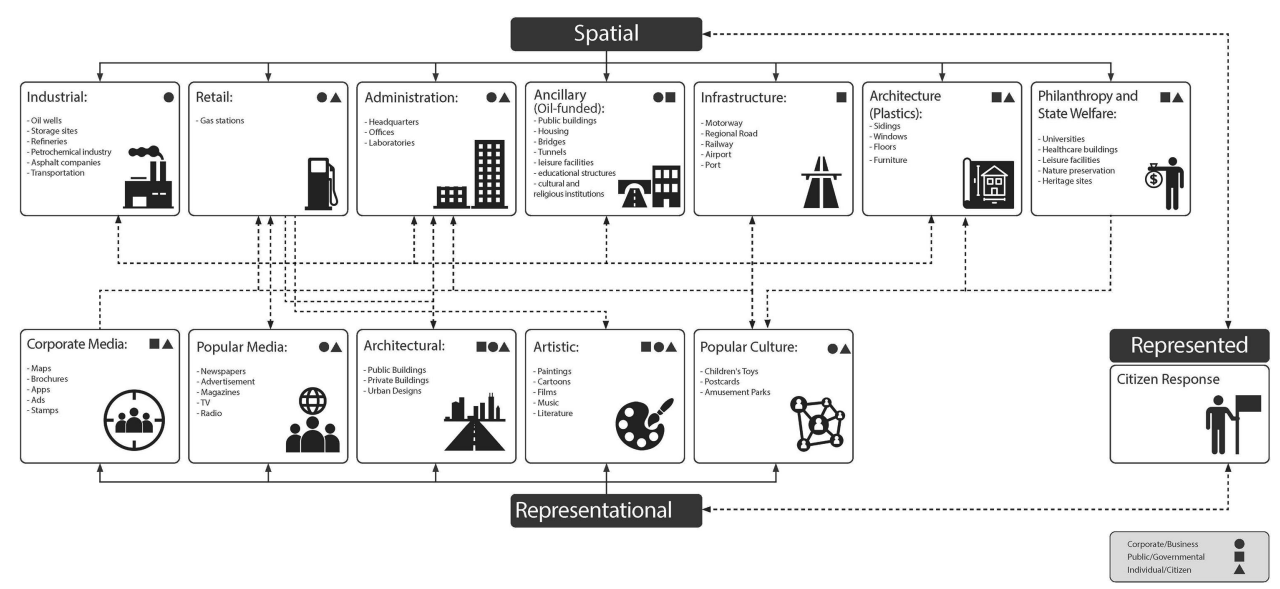

FIGURE 1.1 The hybrid, multiple, shifting, and uneven ways in which many actors collaborate to create the global petroleumscape. Source: Carola Hein.

of the industrial, administrative, retail, and infrastructural petroleumscape form a single global landscape. This spatial presence of petroleum structures and the close collaboration of relevant actors has created path dependencies (to use a concept developed in the political sciences) that reinforce the petroleumscape. Over time and depending on the temporal, geographic, and larger political, economic, social, and cultural context, the various petroleum actors, with the support of the general public, have created an energy culture with multiple feedback loops, both spatial and represented, that stabilize the system, make oil a positive and fun factor of everyday life, and effectively prevent companies and countries from making a transition from oil to other energy sources.

Petroleum has transformed spaces, their representation, and the way we live around the world. These spaces are usually experienced, seen, and discussed separately from each other. They are also promoted by diverse petroleum actors in uneven ways. This separation, I argue, has facilitated the spread of petroleum-based practices. Sites of extraction are far away from the locations of consumption. The benefits of mobility, heating, or plastic use are not obviously related to the pollution and environmental disasters or poor living conditions created by the production of oil. The fact that these different spaces are usually studied and promoted separately in terms of national context, typology, and appearance hides the complexity and interconnectedness of the petroleumscape and makes it easier for international corporations to influence national politics and planning processes. The "nationalization" of what is effectively a single international petroleumscape, the focus on select territories and representations of the petroleumscape, establishes separate bubbles and makes it even more difficult to induce change. The spaces and practices, once created, are key to the petroleumscape feedback loop.

Each layer of the spatial petroleumscape has specific characteristics that are distinct in function, location, land use, scale, typology, urban and architectural form, and financial impact, but they are effectively part of one spatial system. Public and private petroleum actors engage with these spaces in often quite different ways, discussed here under the theme of the representational petroleumscape, that is, the way in which these spaces are communicated to the local and global public. The following section explores the spatial and the 
representational petroleumscape, leaving the represented petroleumscape to later investigation. The interrelation between the spatial and representational petroleumscape facilitates the longevity of the petroleumscape and prevents changes.

\section{The Spatial Petroleumscape}

The concept of the spatial petroleumscape aims to overcome the segmented, monodisciplinary, and localized approach to the spaces of petroleum. It identifies the diverse spaces that are inherent parts of petroleum production, transformation, and consumption, and bring them into conversation. Scholars usually study these realms from different and disconnected perspectives and consequently tend to overlook the petroleumscape's systemic character. Understanding the multiplicity of petroleum spaces and their interconnectedness provides insight into the complex interrelationship and mutual constitution of the spatial networks that support petroleum exploration, transformation, and use. The following sections present and discuss the various spatial elements of the spatial petroleumscape through its industrial, retail, administrative, infrastructural, ancillary, architectural, and philanthropic components.

The industrial petroleumscape has a large spatial extent, including areas on sea and land. Encompassing ships and ports, drilling platforms, storage places, pipelines, and refineries, it is a truly global space with standardized structures that are identical around the world. Port city regions, where maritime transport, oil refining, and landside transportation intersect, are perhaps the most important nodes in the industrial petroleumscape. ${ }^{10}$ Because water is essential both for industrial processes and for shipping, refineries have often been located near rivers. Control over land- and sea-based transportation, including the possession of a shipping fleet, has allowed companies to respond flexibly to their global commodity chains and has served as a geopolitical tool. Industrial structures, such as refineries, require extensive technical knowledge, financing, and expertise. As a result, the industrial petroleumscape is a story of superlatives. Refineries in Pladjoe in Indonesia, Suez in Egypt, and Abadan in Iran were all at some point the largest installations of their kind. The scale of these installations is enormous; the Jamnagar refinery in Gujarat, India, for example, commissioned in 1999, occupies 7,500 acres. ${ }^{11}$ Despite their huge scale and territorial impact, these structures are not accessible to ordinary citizens.

Consumers experience petroleum more closely through the retail petroleumscape. The early petroleum business provided oil for lamps, but this did not lead to a dedicated retail system. With the emergence of the car, gas stations became the industry's most visible retail structure and one that is clearly part of the petroleumscape. Since their emergence in parallel with the spread of the car as a key mode of transport, they have become more recognizable, highly branded, their network serving as an advertisement for oil companies. From flimsy buildings, often designed in keeping with local interests, they have come to integrate the functions of a supermarket, coffee shop, or even wedding center. They serve both land and sea, and gas stations are even located on floating structures that cater to boats. Other forms of petroleum products have entered the retail chain in various ways, from building materials to clothes, and stores of all sizes around the world serve to promote petroleum products.

Perhaps less recognizable than gas stations, but often even more prominent in particular locales, is the administrative petroleumscape, encompassing petroleum company headquarters and research institutes. Prominent local architects have designed many of the buildings in 
line with the predominant taste in corporate or public architecture. These iconic buildings are often located next to each other and next to government ministries, in capital cities, designed in a style characteristic - and sometimes trendsetting-of their time and often similar to that of key administrative buildings nearby. Oil companies have become architectural landmarks in their respective towns and a leading force in the development of business districts. Historic headquarters buildings in prime locations include the Shell-Mex House in London-the clock tower-crowned building that faces the Thames and backs up to the Strand, linking Buckingham Palace and the City. Exxon, a Standard Oil spinoff, has set trends in design and urban location through its regional headquarters. The spatial prominence is aligned with the power of the institutions. Decisions taken in New York, London, or The Hague, in Tehran, Moscow or Caracas, can change global geographies.

If and when necessary for the functioning of the petroleum industry, oil companies have built an ancillary petroleumscape, consisting of diverse structures needed for the functioning of the industry: streets, housing, leisure facilities, or even entire cities, not directly related to the physical or financial flows of petroleum. The city of Abadan in southern Iran is one example. When oil was found in southern Iran, the Anglo-Persian Oil Company (later BP) designed Abadan, a company town between 1910 and 1951. Whereas such investments are necessary in the proximity of extraction sites, they are less needed where housing and office buildings exist and where spaces can be rented, bought, or built to host petroleum clubs (like the Overseas Club), to provide hotel rooms or golf courses to provide spaces for political networking. The case of Caracas with its Avila hotel and golf courses stands as an example: oilmen like Rockefeller and business and political leaders met there with architects and urbanists such as the French Maurice Rotival — who would go on to become a professor at Yale-and Wallace Harrison-Standard Oil's main architect. Both men designed projects for Standard Oil and the Rockefeller family. ${ }^{12}$

The global reach of the petroleum industry requires extensive infrastructures, many of which are not on land owned or controlled by the industry. Road, rail, and pipeline connections as well as bridges, dams, and port infrastructure - the infrastructural petroleumscaperequire public support, often from multiple countries and through different logistics companies. Private oil companies through their economic weight and technological expertise can help reshape global geographies. Rockefeller's Standard Oil built its empire on petroleum transport and refining, rather than on access to oil sources. The Shell company started as a transport company, building, for example, the SS Murex, the first oil tanker to cross the Suez Canal (completed in 1869) in 1892. By using the Suez Canal, Shell was able to compete with the Rothschilds, who were transporting petroleum by train from Russia, and with Standard Oil, which was sending petroleum in barrels around the world. ${ }^{13}$ A close relation between state and oil interests can potentially make it easier to engage with an energy transition-consider Norway-but it can also result in the opposite.

The petroleumscape has constantly evolved. The industry depended on chemical innovation to find new uses for petroleum and to expand its global network. Beginning with the invention of synthetic polymer-based plastics at the beginning of the twentieth century, designers and architects were intrigued by the possibilities for using plastics in building, creating the architectural petroleumscape. Initially, the uses they envisioned ranged from the small scale-light switches and furniture - to whole elements - windows and walls. Chemical companies envisioned a profitable use for their products. Experimentation in all-plastic houses peaked in the late 1950s and early 1960s. Probably the most famous of these was the 
"House of the Future." Its location in Disneyland in southern California guaranteed that it was seen by millions of visitors. Opened in 1957, the powerful collaboration of research, construction, and design of MIT architects, the Monsanto Chemical Company, and Disneyland inaugurated a visionary plastic house of the future with novel forms and technologies that was marketed as part of a modern lifestyle: clean, functional, and fun. Although all-plastic houses were something of a temporary fad, the rapidly growing plastics industry fueled petroleum extraction, shipping, and refining.

Oil industry actors have long been eager to use architectural and urban space to showcase the way in which they-personally or as a company-are beneficial to society, creating a petroleumscape of philanthropy. Investments in health, education, culture, and heritage have become a means of branding and, often, a way to effectively boost the global flows of oil. In parallel with their commercial ventures but consciously and carefully separated from the Standard Oil/Exxon name, the Rockefeller family made architectural gifts to educational, health, and cultural institutions and supported natural and historical sites in key locations, establishing their philanthropic footprint in their headquarters city, New York, but also throughout the US and in many other parts of the world. Their gifts promoted societal transformation and constructed a cultural modernity through physical spaces and carefully built mindscapes in tune with the oil-based transformation of cities and landscapes around the world. Oil corporations similarly invest in diverse structures: on the building scale, these include BP Bridge in Chicago by the world-renowned architect Frank Gehry. They also sponsor educational and cultural spaces, including international schools and museums. This support has been criticized by groups such as Culture Unstained, which aims to end the oil industry's efforts to gain social legitimacy through philanthropy. ${ }^{14}$

\section{The Representational Petroleumscape}

While the concept of the spatial petroleumscape engages the physical presence of petroleum flows and funding, the representational petroleumscape concept explores the ways in which corporate and national actors advertise the spaces and uses of petroleum, and in which public media, private actors such artists and architects, and agents of popular culture influence perceptions of the spatial petroleumscape. This representation of petroleum has changed extensively in line with private and public needs and interests and with cultural practices and their evolution through time and space.

Just as oil companies adapt the spaces of petroleum to specific local needs, they adapt the display of oil spaces to local contexts. The industrial spaces of oil are the object of company advertisements, government publications, and popular media presentations with the focus and amount of this attention shifting over time. In the petroleumscape's early years, when American media addressed petroleum, the focus was largely on the growth of the industry, its financial impact, and advertising. Questions of safety and working conditions received less attention until 1904, when Ida Tarbell exposed the practices of the Standard Oil Company. Demonstrating the power of "muckraking" journalism, a Supreme Court decision in 1911 ultimately broke up Standard Oil into thirty-four separate companies. ${ }^{15}$ But the impact of critical journalism remained limited. Companies and governments quickly claimed the power of the media for themselves. Oil companies made promotional films about their accomplishments, including cities they built and products they created.

As corporations and governments collaborated more intensively in the development of the petroleumscape, many countries started to celebrate their colonial programs, national 
policies, oil exploration, exploitation, and development. The Netherlands documented its colonial endeavor in Indonesia through multiple films, and British popular media documented the buildings and everyday operations involved in the Persian oil exploration effort and life in the British model city Abadan. ${ }^{16}$ Corporate road maps of the 1950s, published by oil companies and freely distributed, showcase the ways in which corporate action weaves together advertising, knowledge, and the public's interest in leisure. As Brian Larkin observes, "Roads and railways are not just technical objects ... but also operate on the level of fantasy and desire." ${ }^{\prime 7}$ As citizens see the apparent benefits of the petroleumscape firsthand, they appear less concerned about negative impacts.

Prior to the mid-twentieth century, artists also depicted the industrial petroleumscape in positive ways. Pride in oil storage and handling seems to have inspired oil paintings of the ports of Rotterdam and Dunkirk that document the emerging petroleumscape. ${ }^{18}$ Artistic representations of the benefits of petroleum are prominent in China, Russia, and many countries of the Middle East. Celebrating the scale and the power of oil infrastructure has been key to national narratives in various parts of the world at select moments in time. In countries where the oil company is owned by the state, this becomes even more visible; in China or Iran, for example, images of refineries on money or stamps have been a key part of everyday experience. In line with the contemporary assessment of petroleum use as environmentally damaging, some companies have started to debrand this industrial landscape, for example, by removing the logos from oil storage tanks. This is in line with companies' attempts to promote the idea that their products are environmentally friendly when they are not (which critics refer to as "greenwashing").

Critical artistic approaches to the petroleumscape can help raise awareness of the enormous scale of oil's presence and its representation in order to support new energy values in line with a post-oil society and to create new imaginaries of post-oil life. Engaging with our ongoing research on the petroleumscape in the Netherlands, a young illustrator, Jenna Arts, created two illustrations that capture the Dutchness of oil, translating Vermeer's milkmaid into an oil maid, and adding a gas station into Vermeer's Little Street of Delft (Figure 1.2). These illustrations speak to the extent to which the consumer has become a partner complicit in the feedback loop of the petroleumscape and raise the question: What would the post-oil equivalent of this maid or of this street look like?

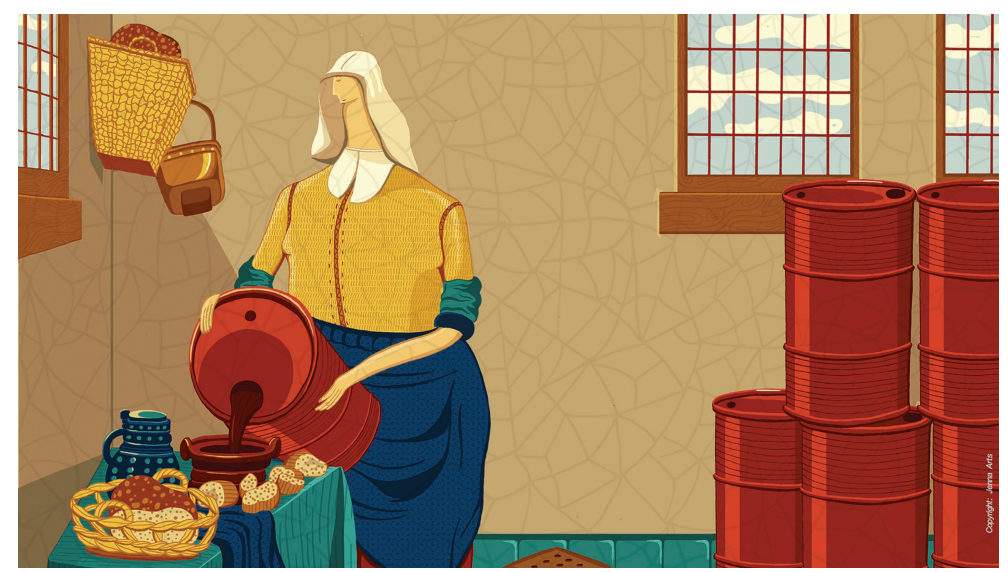

FIGURE 1.2 Reinterpreting well-known works of the Dutch artist Vermeer, Jenna Arts aimed to capture the Dutchness of the representational petroleumscape. Source: Jenna Arts 
Architects, including famous ones, have produced their own commentary on the emerging petroleumscape, often at the invitation of the petroleum or car industry or in support of them. The influential visionary project for a city with skyscrapers and highways, the Cité Voisin plan by Le Corbusier, was sponsored by a car manufacturer. Cars were also a key feature in Frank Lloyd Wright's Broadacre City. The most striking connection between oil, cars, and city planning was made by the City of the Future project for the 1939 World's Fair in New York. It resulted from a collaboration between General Motors, designer Norman Bel Geddes, and Shell Oil, who used the imagery for advertising purposes. Featuring a modern city of highways and skyscrapers, the exhibit went on to inspire planners in shaping real cities and encouraged citizens to imagine how to live in the second part of the twentieth century. At the same time, the petroleum industry, along with other private and public players, was lobbying for oil-friendly public policies like subsidies for highways and against public transit. Together with the heavily promoted desire for the single-family home-and in the US, federal mortgage deals for veterans in the postwar period-these were a recipe for increased driving and suburban sprawl.

Architects have drawn inspiration from the petroleum industry for new designs of nonpetroleum buildings since the 1960s. For example, visionary drawings by Archigram and the plug-in city by Peter Cooke in 1964 are reflections on refineries, with an example depicted in Archigram's publication. Actual buildings, such as the Centre Pompidou in Paris designed by Richard Rogers and Renzo Piano and finished in 1967, show the degree to which architecture accepted the aesthetics of refineries. The Norwegian Oil Museum in Bergen, built in 1999, with its oil tank-like features, explicitly recalls oil structures.

Popular culture merits further investigation, forming part of the representational petroleumscape's affective qualities - both positive and negative. Think of children's toys produced without direct collaboration of the oil companies: a puzzle featuring an oil refinery, a toy car with the Esso logo, a Lego car handed out at a Shell gas station, or plastic Barbie houses that might eventually inspire their owners to choose plastic window frames, furniture, or floor coverings. Such objects promote the recognition of oil buildings, logos, and colors from an early age, preparing children for an oil world, albeit without displaying the oil or shipping flows that drive it. Greenpeace understood this relationship when the organization made a film called "LEGO: Everything is NOT Awesome," praising the dissociation of Lego from Shell. ${ }^{19}$

The degree to which the spaces of petroleum have entered the represented petroleumscape merits further investigation. Identifying and analyzing the individual spatial and representational elements of oil constitutes a first step in better understanding the impact of oil and in shaping our future energy spaces and practices.

\section{Book Overview}

In three distinct parts, the chapters in this volume provide insights into the territoriality, agency, practices, and imaginaries of petroleum through case studies. Building on unpublished primary sources and considering questions of (energy) landscapes, they bring architecture and urbanism into a sustained dialogue with humanities scholarship. This detailed investigation of the spaces and representations of petroleum gathered in this volume represents a foray in understanding the multiple and complex ways in which petroleum shapes contemporary spaces and practices. The impact of petroleum on global space is too vast to be 
fully examined in a single volume. A topic as complex as the global petroleumscape requires global and multidisciplinary collaboration based on shared approaches, and the contributions assembled here can only be seen as a preliminary investigation.

Part I on Oil, Agency, and Territoriality investigates questions of territories, boundaries, and policy in reshaping global geographies over time. It demonstrates how public and private actors have created the diverse spaces of the petroleumscape, creating spatial patterns and select nodes to facilitate petroleum flows, transformation, and use. Depending on political systems - capitalist, socialist, communist - and the position of the oil company in relation to the state, but also countries' environmental, social, and cultural preferences, the clustering of oil functions has varied through space and time.

This section starts with an exploration of the first petroleumscape in North America. Carola Hein and Alan Lessoff discuss a key example of petroleum-fueled spatial growth and the emergence of new practices focusing on the period from the 1850 s to the 1950s. Ben de Vries probes the intricate intersection of national lust for petroleum and the construction, destruction, and reconstruction of petroleum's infrastructure through the case of the Pladjoe petroleum cluster in the turmoil of the 1940s in the colony of the Dutch East Indies, now Indonesia. He shows how petroleum resources tend to encourage military conflict that damages a petroleumscape, but it can be quickly restored and its longevity assured with the collaboration of diverse stakeholders. Stephen Ramos continues this trajectory, exploring the interrelated and dynamic processes of territory, territoriality, and sovereignty in the Persian Gulf region from the pre-oil period through periods of oil exploration, discovery, and industry consolidation to the 1970s. The multiple layering of Gulf territorial signification simultaneously combined British national and imperial objectives with the corporate objectives of interested oil companies and the establishment of constituent pre-nation-state urban, territorial, and legal frameworks. Giulia Scotto analyzes an aspect of the global scale of the petroleumscape as she investigates the grande disegno africano implemented by ENI (Ente Nazionale Idrocarburi), Italy's national hydrocarbon agency, showing how the company shaped territories and lived experience in postcolonial Africa, specifically Ghana, Tanzania, and Zambia in the 1960s. The chapter studies typologies, spaces, and scales often neglected by architectural historians. Nancy Couling expands the exploration of territoriality to the sea, where oil installations-drilling platforms and pipelines-form part of the offshore petroleumscape - a fifty-year-old historical format that has urbanized the entire North Sea since the 1960s. She emphasizes the need to expand the petroleumscape concept to include the sea, not only as a place of extraction and transport, but also of urbanization and of the reuse and reimagination of these structures.

Part II on Oil, Materiality, and Cultural Practices explores oil's direct and indirect influence on built spaces, commodities, and lived experience through the lens of oil-rich and oil-connected areas in Africa, the Middle East, Brazil, China, and Europe. They explore changes and continuities in colonial and postcolonial frameworks and how struggles for sovereignty have often reproduced colonial notions of progress and modernity. Petroleum companies played an important role in establishing housing districts and promoting consumer goods and new lifestyles as they developed extraction sites and as petroleum funds led to the construction of new cities. The growth of the industry imparted a new direction to and intensified the circulation and exchange of people, commodities, and technical and scientific knowledge, playing a key role in the creation of a new urban space and new kinds of societies, inside and outside oil towns. 
Aspects of continuity and similarity in the import of new objects and practices such as cars and consumer items play an important role in Nelida Fuccaro's investigation of oil company towns built by foreign multinational oil companies. These company towns contain the traces of an early petroleum modernity closely associated with Western imperialism, old style colonialism, and industrial urbanism in the post-World War II period. Drielli Peyerl examines the case of Brazil, where the government focused on energy independence, and beginning in the 1930s, "designed" the petroleumscape based on a vision that connected infrastructure construction with drilling, hinterland development, and modernization with promotion of research and education. Laura Hindelang explores the respective approaches and displays of water and oil through infrastructure in Kuwait City, arguing that the visual-spatial absence of oil obscured the two fluids' interdependent conditions of existence, helping water to become the representative liquid of Kuwait's oil-based modernization in the 1950s-1970s. Christoph Strupp complements this investigation with his study of the marketing of Hamburg as a clean-not industrial—port. Oil played a strong role in the port and in local economic politics in the 1950s and 1960s, and effectively it remains an oil port, but highlighting that is no longer seen by the government as in the local interest. Turning to China, Li Hou provides a close study of Daqing's state-sponsored industrialization strategies that bound the lives and life choices of the common people with the fate and choices of the consolidating socialist state, providing a contrast with the predominant association of oil with consumerism, corporate power, and suburbia in the 1960s and 1970s. It shows how a government can use its construction of a petroleumscape for its own promotion.

Part III on Oil Ecologies and Imaginaries connects the exploration of oil systems to challenges of the energy transition and projects for overcoming them. A critical part of the transition away from oil is education about its actual history: raising awareness of the extent to which it shapes our everyday lives, the costs and effects of its ubiquity, and the power of the ongoing propaganda pursued by oil companies. We need to design the transition and make the spaces of post-oil just as pervasive, heroic, and appealing as the spaces of oil. In place of petroleum and its narratives, we need to close circles of consumption and production to create circular economies, lessen the use of fossil fuel, reduce petroleum-based plastic waste to stop an energy-intensive lifestyle, guarantee water safety, and reduce hunger in line with the UN Sustainable Development Goals.

Imre Szeman and Caleb Wellum start the section by reflecting on the field of energy humanities and its quest to understand the essential role that energy (not just petroleum) plays in our lives and the significance for the investigation of oil spaces. Pieter Uyttenhove explores carbon (diamonds as well as petroleum) in Antwerp to help us understand the connection between petroleum spaces, their use, preservation, reuse, and clean-up, but also because the imaginary of petroleum, including its smell and dangers, plays an important role in the way the public views the city. He relates the port's carbon history to its history of promoting itself as the biggest and best (as evidenced in statistics). Chiara Geroldi and Gloria Pessina reflect on the power station of Porto Tolle in the Po River delta of northern Italy, one of twenty-three unused or underused Enel power stations, which were fueled by oil to produce electricity and now have been designated for redevelopment. The chapter recognizes the need to see rural power stations as a symbol of petroleum-based modernity connecting remote spaces through petroleum-related infrastructure to consumers. Carola Hein, Christine Stroobandt, and Stephan Hauser consider the important role of port cities 
in the emergence of the petroleumscape. They aim to show how a careful historical analysis, in this case of the petroleum flows in Dunkirk, can help inform design solutions for the future-both visionary sketches and concrete ideas.

\section{Outlook}

The chapters brought together in this volume form a coherent whole while addressing a complex global topic. They cannot be all-encompassing, but aim to create interest. Focused on a shared topic and grounded in local knowledge, the chapters represent a wide variety of perspectives. The book includes case studies from five of the seven top oil-producing countries (the US, Canada, Brazil, Indonesia, and Saudi Arabia) and explores the petroleumscape of several European countries and of China, Kuwait, and Africa. There are many more places that have played important roles in the global petroleumscape that have not been included here. This book is an invitation for further exploration of the spaces of oil in Russia, Iraq, Nigeria, Venezuela, and many other places.

Increased burning of fossil fuels and the creation of carbon dioxide play a big part in contemporary global warming and environmental pollution. Oil leaks can harm the natural environment, regardless of whether they are caused by ship crashes, pipeline breaks, or the spilling of gasoline in an everyday setting. Rising petroleum costs, global warming, the leading industrial countries' dependence on foreign oil, and the impending peaking of oil (if it has not already occurred) have led to an initial rethinking of energy sources, which, in turn, may lead us to once again transform our landscapes and built environment. If we want to change, we need to understand where we stand and how we got to this point. We need to understand how petroleum has been written into spatial practice and representations, both global and local, serial and unique, long and short terms, but always in a way that is interconnected and interdependent.

A close analysis of the spatial, representational, and represented petroleumscape can help create new perspectives on the role of energy spaces and facilitate the development of new systemic approaches. We need to better understand the path dependence that underlies its development over time and the forces that impede us from fully committing to the transition to sustainable energy spaces and practices. We need structural change rather than piecemeal interventions. Such an understanding is important not only for the design of a green energy landscape, but also as a foundation for heritage decisions. Many historic oil sites are now becoming part of our history and our cultural heritage. We need to make informed decisions about the fate of these sites. To do that, we need to tease out a new vocabulary of conceptual understanding: of petroleum spatial systems, tangible and intangible spaces, oil materiality, oil ecologies, the energy humanities. We can design a transition that promotes circularity and sustainability in a socially just way and develop new narratives about eco-friendly materials to promote new creative practices.

\section{Notes}

1 Carola Hein, "Between Oil and Water. The Logistical Petroleumscape," in The Petropolis of Tomorrow, eds. Neeraj Bhatia and Mary Casper (New York: Actar/Architecture at Rice, 2013), 436-47; "Global Landscapes of Oil," New Geographies 2 (2009): 33-42; "Oil Spaces: The Global Petroleumscape in the Rotterdam/the Hague Area," Journal of Urban History 44, no. 5 (September 2018): 887-929, https://doi.org/10.1177/0096144217752460; “'Old Refineries Rarely Die’: 
Port City Refineries as Key Nodes in the Global Petroleumscape," Canadian Journal of History 55, no. 3 (2018): 450-79, DOI:10.3138/cjh.ach.53.3.05.

2 Daniel Yergin, The Prize (New York: Simon \& Schuster, 1991); Brian C. Black, Crude Reality: Petroleum in World History (Lanham, MD: Rowman \& Littlefield, 2012); Anthony R. Walker, "Oil-Dependent Economies and Port Development," in Seaport Systems and Spatial Change: Technology, Industry and Development Strategies, eds. Brian S. Hoyle and David Hilling (Chichester: John Wiley \& Son, 1984), 179-97; M. Hubbard, The Economics of Transporting Oil to and within Europe (London: Maclaren \& Sons Ltd., 1967); Timothy Mitchell, Carbon Democracy: Political Power in the Age of Oil (London: Verso, 2013); Matthew T. Huber, Lifeblood Oil, Freedom, and the Forces of Capital (Minneapolis: University of Minnesota Press, 2013); Drielli Peyerl, The Oil of Brazil. Exploration, Technical Capacity and Geosciences Teaching (1864-1968) (New York: Springer, 2019); Farah Al-Nakib, Kuwait Transformed: A History of Oil and Urban Life (Redwood City: Stanford University Press, 2016).

3 Neil Brenner and Christian Schmid, "Towards a New Epistemology of the Urban?," City 19, nos. 2-3 (2015): 151-82; "Planetary Urbanization," in Urban Constellations, ed. Matthew Gandy (Berlin: Jovis, 2011), 10-13.

4 Nancy Couling and Carola Hein, eds., The Urbanisation of the Sea: From Concepts and Analysis to Design (Rotterdam: nai010/BK Books, 2020).

5 Arjun Appadurai, "Disjuncture and Difference in the Global Cultural Economy," Theory, Culture E Society 7, nos. 2-3 (1990): 295-310, https://doi.org/10.1177/026327690007002017.

6 Michael J. Watts, "Crude Politics: Life and Death on the Nigerian Oil Fields," Niger Delta Economies of Violence Working Papers 25 (2009): 1-27; Janet Stewart, "Making Globalization Visible? The Oil Assemblage, the Work of Sociology and the Work of Art," Cultural Sociology 7, no. 3 (2013): 363-84.

7 Henri Lefebvre, The Production of Space (Oxford: Blackwell, 1991), 26-27.

8 Ibid.

9 Lukasz Stanek, Henri Lefebvre on Space: Architecture, Urban Research, and the Production of Theory (Minneapolis: University of Minnesota Press, 2011); Lefebvre, Production of Space; Henri Lefebvre, A Critique of Everyday Life (London: Verso, 1991).

10 Hein, "Between Oil and Water."

11 Praveen Duddu, "Top 10 Large Oil Refineries," Hydrocarbons Technology, hydrocarbonstechnology.com/features/feature-top-ten-largest-oil-refineries-world/, accessed 10 July, 2018.

12 Carola Hein, "Maurice Rotival: French Planning on a World-Scale (Part I)," Planning Perspectives 17, no. 3 (2002): 247-65, DOI:10.1080/02665430210129315; "Maurice Rotival: French Planning on a World-Scale (Part II)," Planning Perspectives 17, no. 4 (2002): 325-44, DOI:10.1080/02665430210154740.

13 Carola Hein, "Suez et la route du pétrole," in Suez, ed. Claudine Piatone (Cairo: Institut Francais d'Archeologie orientale, 2011).

14 Culture Unstained, "Home," https://cultureunstained.org/, accessed 22 December, 2020.

15 Ida M. Tarbell, The History of the Standard Oil Company (New York: McClure Phillips, 1904).

16 Willy Mullens 1924, Haghe Film (Den Haag), FLM5699; C.W. A. van Bergen 1930-1932 | Production Company: unknown | Film from the collection of EYE (Amsterdam), https://www. eyefilm.nl/; 1920s Abadan, Iran: Abadan Streets Iran, 1950s - Film 99068; Leisure And Work In Abadan Iran, 1950s - Film 99069, Huntley Film Archives.

17 Brian Larkin, "The Politics and Poetics of Infrastructure," Annual Review of Anthropology 42 (2013): 327-43.

18 Carola Hein, "Oil in Oil (and Other Art Media): Painting the Petroleum Port," PortCityFutures (20 October, 2020), https://www.portcityfutures.nl/news/oil-in-oil-and-other-art-mediapainting-the-petroleum-port.

19 Greenpeace, "Lego: Everything Is Not Awesome," https://www.youtube.com/watch?v= qhbliUq0_r4, accessed 22 December, 2020. 